\title{
Ceramics Bonding Using Solder Glass Frit
}

\author{
Z. SUN, ${ }^{1,2}$ D. PAN, ${ }^{1}$ J. WEI, ${ }^{1}$ and C.K. WONG ${ }^{1}$ \\ 1.-Singapore Institute of Manufacturing Technology, Singapore 638075. 2.—E-mail: zsun@ \\ simtech.a-star.edu.sg
}

Ceramics bonding is becoming an important technology and has found wide applications in different engineering and electronic industries. In this paper, furnace bonding of ceramics using solder glass frit was investigated with emphasis on the effects of surface treatment and bonding conditions on bonding strength. Alumina $\left(\mathrm{Al}_{2} \mathrm{O}_{3}\right)$ sheet and SCHOTT solder glass G017-393 were used as the base and brazing filler materials, respectively. Chemical surface treatments using various acids were tested. The results reveal the effects of spreading and voids on bonding strength. An optimum bonding strength can be produced by an appropriate combination of bonded glass-frit density and spreading area. Bonding strength is not only related to surface-contact angle but also surface roughness. The study shows that high-quality ceramics bonding or sealing can be achieved with the application of appropriate bonding conditions.

Key words: Ceramics, bonding, surface treatment, solder glass frit, processing parameters, surface roughness, surface-contact angle

\section{INTRODUCTION}

Like some advanced ceramics, glass has also exerted a formative influence on the development of various industries, particularly in optics, electronics, chemistry, and pharmaceutics. ${ }^{1-7}$ It has been realized that glasses, especially those used to enhance densification during sintering, have potential to join ceramic components. One of the advantages of using these glass materials as fillers for joining is that chemical compatibility with the parent ceramics is generally assured. Other advantages are that the viscosity, flowability, and melting characteristics of glasses can be controlled over wide ranges, and adherence of the glasses to the ceramics is usually quite good. Another desirable feature of glasses is that many compositions can be crystallized to improve their mechanical and corrosive properties. Some successful cases, but not many, were reported, which mainly involved bonding alumina $\left(\mathrm{Al}_{2} \mathrm{O}_{3}\right)$ to metals, alumina to glasses, zirconia $\left(\mathrm{ZrO}_{2}\right)$ to zirconia, and silicon nitride $\left(\mathrm{Si}_{3} \mathrm{~N}_{4}\right)$ to silicon nitride. ${ }^{8}$ However, their bonding temperatures ranged from $1,200^{\circ} \mathrm{C}$ to $1,700^{\circ} \mathrm{C}$. This means that the glass fillers (or intermediates) used in these

(Received March 18, 2004; accepted June 25, 2004) experiments served as brazing materials, based on the definition of brazing.

Solder glasses are specially designed for joining glass to other glasses, ceramics, or metals at lower temperatures, which is attributed to the lower softening point of the glasses. It is expected that the materials to be joined will not be thermally damaged during bonding. ${ }^{7,9}$ Therefore, it has many potential applications in electronics packaging. Although many efforts have been concentrated on diffusion, electrostatic (or anodic), and eutectic bonding of ceramics, ${ }^{8,10,11-16}$ the relevant literature focusing on low-temperature ceramics furnace bonding using solder glasses is rather limited. ${ }^{14,17}$ As a matter of fact, ceramics bonding using solder glasses can be a cost-effective process. ${ }^{5,8}$

Like other ceramics joining techniques, ceramics bonding using solder glasses is also a field where much research and development work is in progress. However, only a few examples have achieved widespread commercial applications. ${ }^{8}$ One of the important issues is that the so-called solder glasses are not truly solders because their melting points can (and frequently do) exceed the highest soldering temperature, $450^{\circ} \mathrm{C}$, which was specified by the definition of soldering. Therefore, the bonding temperatures fall in the range of brazing temperature. Moreover, 
during bonding, the so-called solder glasses do not flow by capillary action, ${ }^{5,18}$ which implies that the mechanism of the ceramics bonding using the solder glasses is likely to be fundamentally different from that of typical brazing and soldering processes, and the mechanism needs to be investigated.

The objective of the present paper is to investigate the effect of bonding parameters on the bonding strength of the ceramic joints using solder glass frit. These parameters include substrate surface conditions (surface treatment media, roughness, and contact angle) and bonding conditions (temperature, time, and applied load).

\section{MATERIALS AND EXPERIMENTAL PROCEDURES}

An alumina (96\% of $\mathrm{Al}_{2} \mathrm{O}_{3}$, Rubalit 708S, CeramTec AG, Marktrendwitz, Germany) sheet of 1-mm thickness was used as the substrate material. Commercially available diamond scriber was used to cut the alumina sheet into 1 in. $\times 1$ in. substrates.

To study the effect of surface treatment, various acids were tested, namely, hydrofluoric acid ( $\mathrm{HF})$, sulfuric acid $\left(\mathrm{H}_{2} \mathrm{SO}_{4}\right)$, and phosphoric acid $\left(\mathrm{H}_{3} \mathrm{PO}_{4}\right)$. Before acid treatment, all of the original substrates in the form of as-received were ultrasonically alkalinecleaned for 15 min by soaking the substrates in a solution containing commercially available detergent. Then, the substrates were completely rinsed by deionized water. After this, the substrates were ultrasonically treated in a solution of specified acid for $30 \mathrm{~min}$. All the substrates were completely rinsed by deionized water after the acid treatment, then dried, and stored in a dry cabinet.

After the surface treatment, surface-contact angle and surface roughness were measured. A RAMEHart, surface-contact angle goniometer (model 10000-115, Mountain Lake, NJ) was used to measure surface-contact angles of various substrates using deionized water. Atomic force microscopy (AFM) was used to measure the surface roughnesses of various substrates. For both tests, three locations on each substrate were randomly selected and measured.

SCHOTT solder glass G017-393 in the form of frit (with an average particle size of $10 \mu \mathrm{m}$ ) was used as filler material. The solder glass-frit paste was prepared by mixing an appropriate amount of the solder glass frit with a solution containing $80 \%$ (in volume) of terpineol and 20\% (by volume) of styrene. The slurry was dispensed on one of the two substrate surfaces before joining using a stainless steel scriber and a stainless steel stencil. In this way, a 0.5 -mm-thick slurry layer with an area of $6 \mathrm{~mm}$ in diameter was formed (Fig. 1). The slurry layer was naturally dried in the air.

A fixture was specially designed and fabricated using heat-resistant stainless steel, which has the function of accurately positioning and clamping the substrates to be joined. To control the clearance between the two substrates, a wide range of dead weight can be accurately applied during bonding.

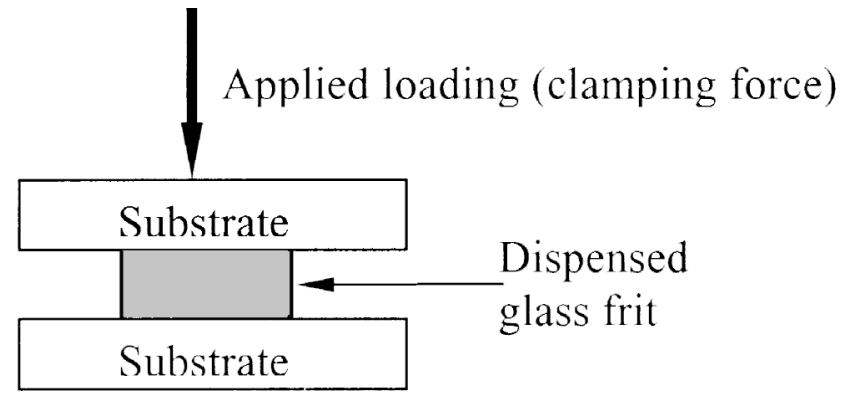

Fig. 1. Schematic illustration showing the arrangement of solder glass filler before bonding.

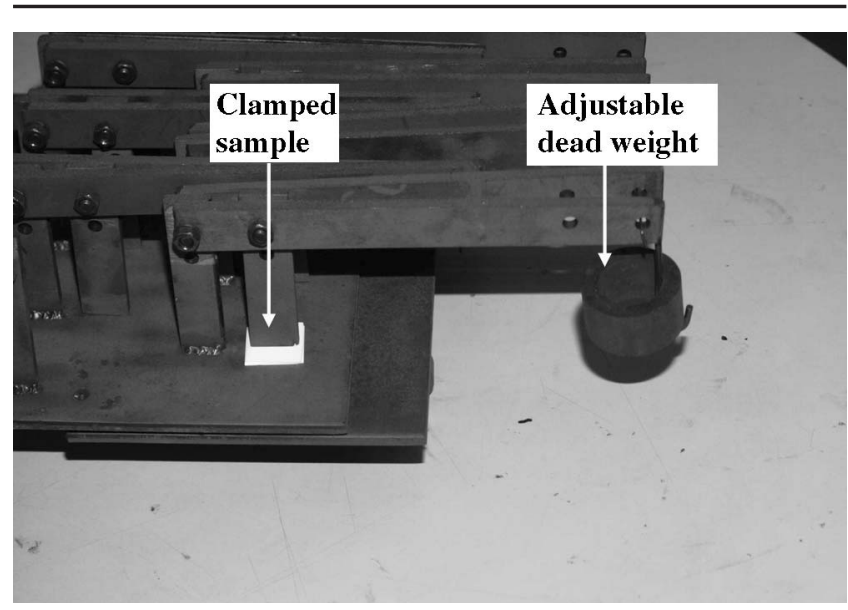

Fig. 2. Fixtures used for furnace bonding of ceramics.

The fixture is capable of holding up to 15 pairs of samples in one batch (Fig. 2).

A Nabertherm electrical-heating box furnace (model: N81/13S, Lilienthal, Germany) was used to perform the bonding (or brazing) process. The furnace was calibrated with a tolerance of less than $5^{\circ} \mathrm{C}$. Both heating and cooling speed were set at $\leq 5^{\circ} \mathrm{C} / \mathrm{min}$. In the course of the whole bonding process, the furnace was set to hold $15 \mathrm{~min}$ at $425^{\circ} \mathrm{C}$ during heating and $15 \mathrm{~min}$ at $325^{\circ} \mathrm{C}$ during cooling, respectively. Various bonding conditions, such as bonding temperature, bonding time, and applied load (clamping force), were investigated. Figure 3 shows the bonding thermal cycles. For each set of parameters, at least three pairs of samples were tested.

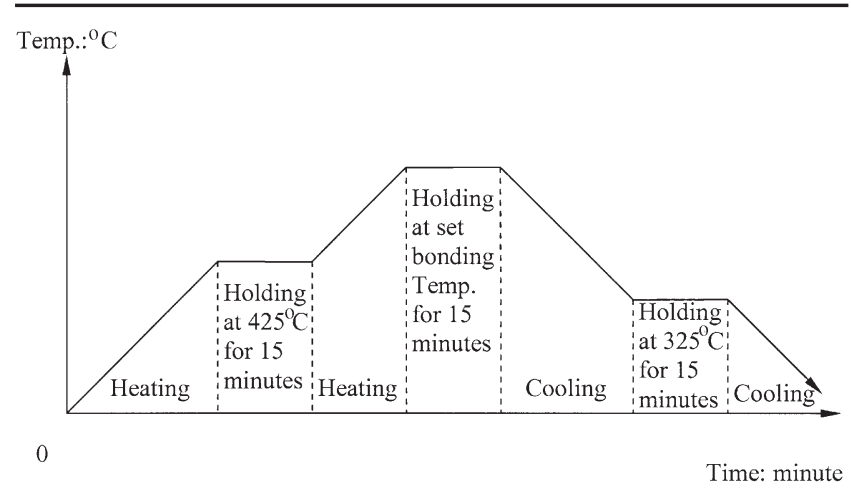

Fig. 3. Furnace-bonding thermal cycles. 


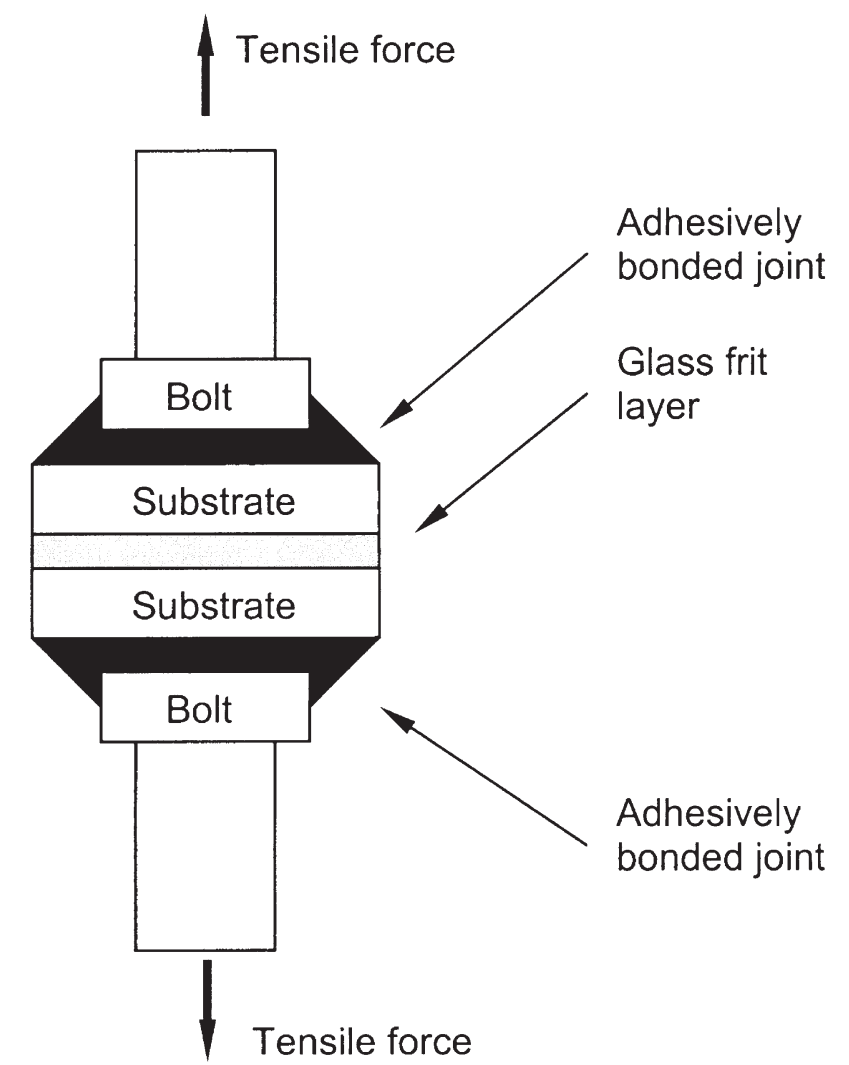

Fig. 4. Schematic illustration showing the arrangement of tensile testing samples.

An Instron tensile-testing machine (Canton, MA) was used to measure the bonding strength of the bonded joints. To obtain accurate values of the rupture force of the bonded joints, each side of the joint was adhesively bonded with a bolt symmetrically (Fig. 4), and the bolt is perpendicular to the substrate. Before starting the tensile test, the two bolts were connected to the two joint nuts clamped by the chucks of the machine, respectively. Three tests were conducted for each type of joints. The tensile strength for each joint was derived from the rupture force and corresponding outlined spreading area of the glass frit. It should be emphasized that only the tensile strength of a dense joint represents its real tensile strength. It is impossible to work out an exact tensile strength for a porous joint if the preceding derivation is applied. Because there are varieties of ruptured-joint morphologies, the rupture force is the only index that can be used to scientifically evaluate the potential bonding strength of the joint.

\section{RESULTS AND DISCUSSION}

\section{Surface Roughness}

Figure 5 presents the detailed measurement results for various substrates. It can be apparently seen that all the surface roughness was reduced after surface treatment, compared to that of the asreceived substrate. The effect of the treatment using different acids seems to be similar, i.e., the changes

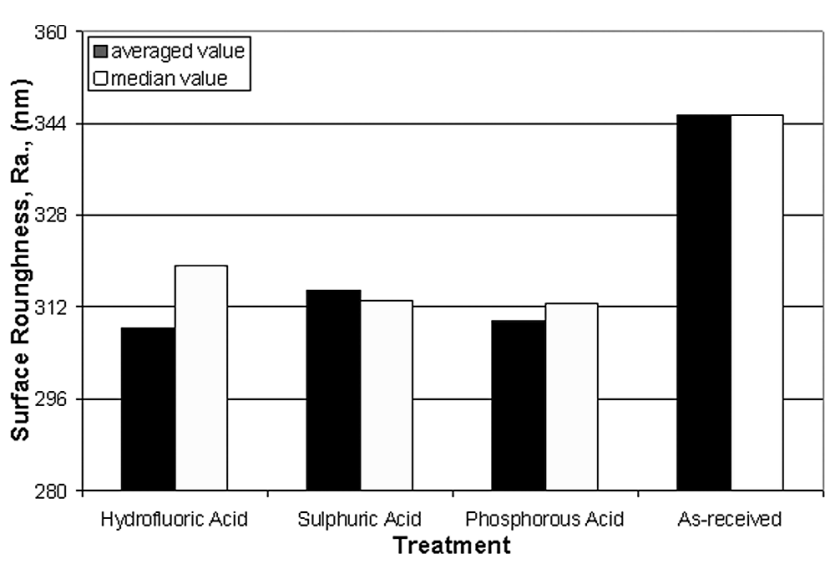

Fig. 5. Surface roughness for substrates with various acid treatments.

in roughness are generally in the same level for the substrates with different acid treatment. This is probably attributed to the chemical reactions to the substrate surface, which involve exchange, erosion, and absorption processes. ${ }^{10}$ In another word, the chemical resistance of the substrate against these three types of acids is quite similar.

\section{Surface-Contact Angle}

As one of the major properties of the surface, the surface-contact angle of the samples treated by various acids was measured. The detailed results of measured surface-contact angle are shown in Fig. 6. It can be seen that all the surface-contact angles of the treated substrates are reduced compared to that of the as-received substrate. The treatment with HF has the strongest effect on reducing surface-contact angle, with a contact angle of zero, while the treatment with $\mathrm{H}_{2} \mathrm{SO}_{4}$ acid has the least effect. This is probably ascribed to the change of surface chemical composition caused by selective etching of components and surface roughness.

\section{Morphology of the Ruptured Joints}

For the tensile test in this study, all the fractures occurred in the glass-frit bonded joints rather than the adhesively bonded joints. It means that the tests

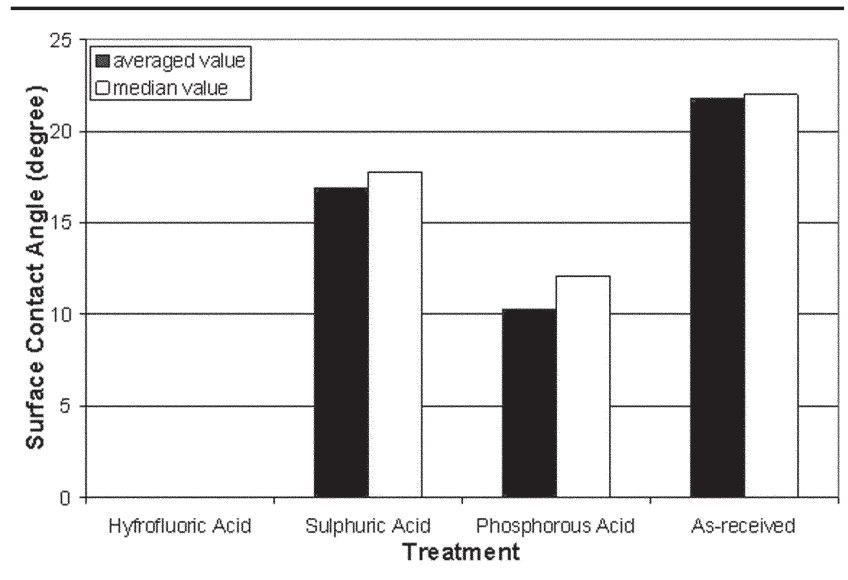

Fig. 6. Surface-contact angles after various treatments: (a) micrographs of mirror-ruptured surfaces and (b) high-magnification micrograph of ruptured surface. 
were successfully conducted and all the values are the real rupture forces. According to the morphology of the ruptured joints, they can be generally categorized into five groups, namely, dense, less dense, less porous, porous, and very porous, based on the fraction of the voids in the joint for $0 \%$, less than $5 \%$, less than $30 \%$, less than $40 \%$, and up to around $50 \%$, respectively. Having carefully observed all the ruptured joints using conventional optical microscopy, it can be verified that all the ruptured joints are characterized by either fracture in the interface between the glass frit and the substrate for those dense and less dense joints (Figs. 7 and 8) or fracture in the glass-frit layer for those less porous, porous, and very porous joints. This can be demonstrated by the identical images in two halves of each ruptured joint (Figs. 9-11). The corresponding highmagnification pictures are shown accordingly in these figures.

\section{Effect of Surface Treatment on Bonded Joints}

The effect of acid treatment on bonded joints is shown in Fig. 12. All these samples were prepared in one batch, i.e., the identical conditions $\left(525^{\circ} \mathrm{C} \times 15\right.$ min $\times 5 \mathrm{~kg}$ ) were applied. All the ruptured joints were shown to be porous, while the as-received sample was less porous. The as-received sample has the

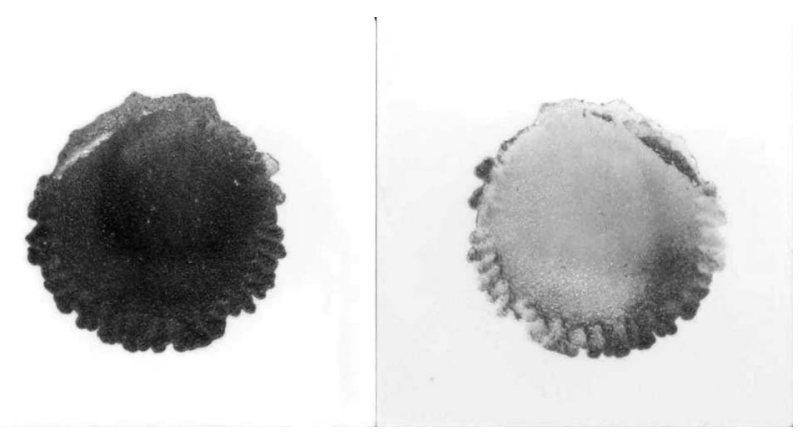

a

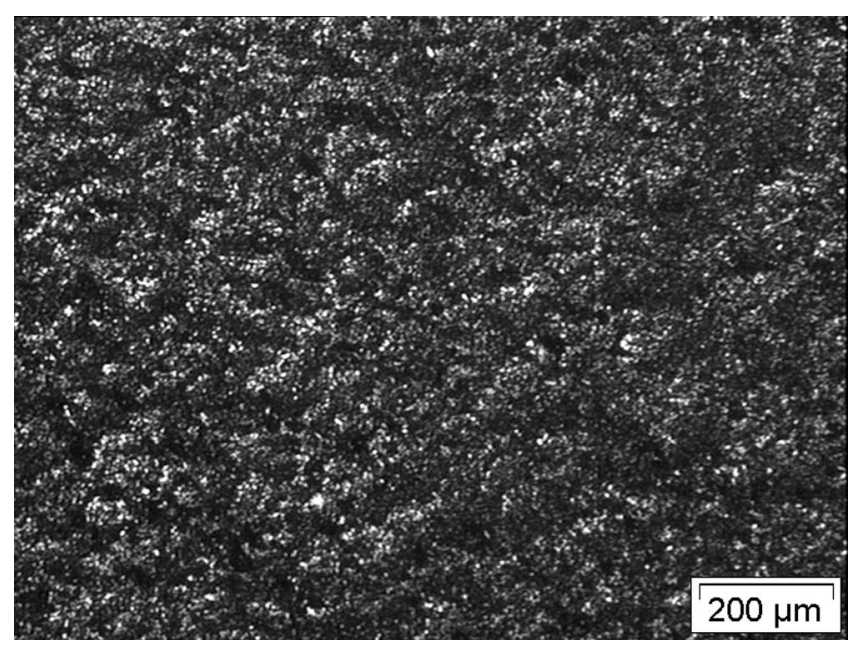

b

Fig. 7. Micrographs of ruptured surfaces of a dense joint: (a) micrographs of mirror-ruptured surfaces and (b) high-magnification micrograph of ruptured surface. highest values in both surface roughness and surface-contact angle; however, it has the highest values of rupture force compared to the other samples. Compared to Figs. 5 and 6, there is a general correlation between rupture force (or bonding strength) and surface roughness, but no correlation between rupture force (or bonding strength) and surface-contact angle (wettability). This means capillary effect is not applicable here. To verify this phenomenon, additional tests using another kind of glass frit (SCB-15 ground-glass powder) made by SEM-COM Company, Inc. (Toledo, $\mathrm{OH}$ ) were conducted (at $425^{\circ} \mathrm{C} \times 15 \mathrm{~min}$ $\times 5 \mathrm{~kg}$, in which the bonding temperature was recommended by the vendor). It should be mentioned that the particle size of the SCB-15 ground-glass powder is much finer than that of the SCHOTT glass frit. The tensile testing results for the SCB-15 glass powder are shown in Fig. 13. The test results show an identical phenomenon as those for the SCHOTT glass frit. The morphologies of the fracture surfaces are also similar to those of the SCHOTT glass-frit samples, i.e., all the joints are shown to be porous except the as-received sample with less porous. This substantially demonstrates that the test results for SCHOTT glass frit are reliable.

It should be pointed out that the bonding strength of a brazed, soldered, or adhesively bonded joint can-

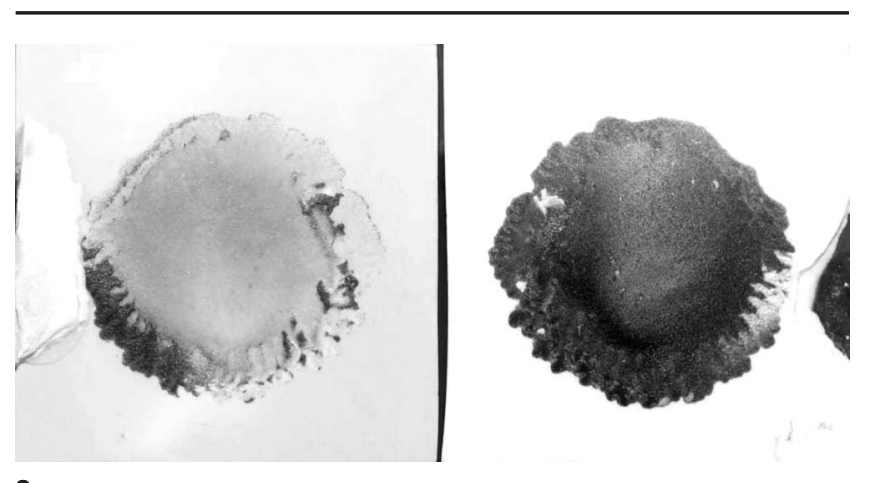

a

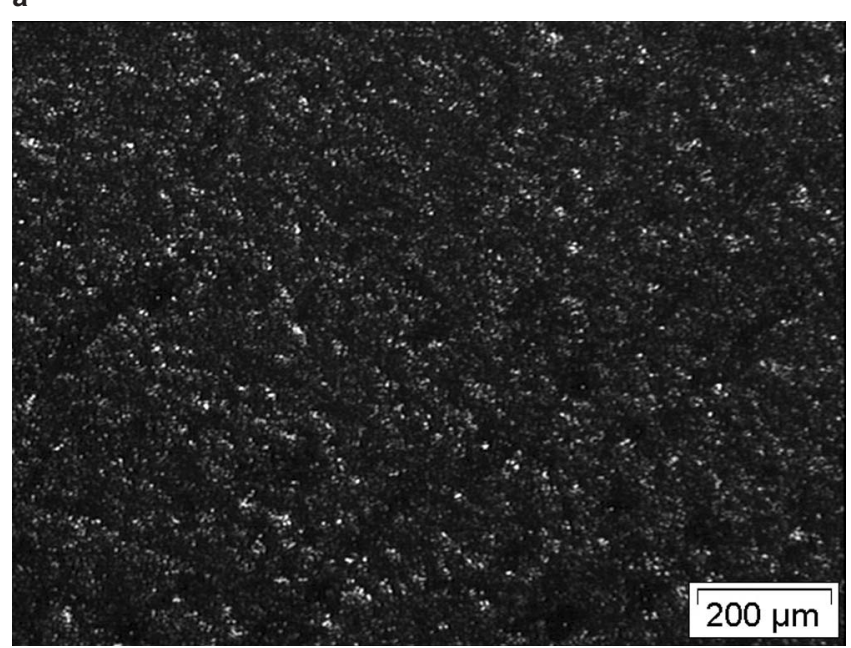

b

Fig. 8. Micrographs of ruptured surface of a less dense joint: (a) micrographs of mirror-ruptured surfaces and (b) high-magnification micrograph of ruptured surface. 

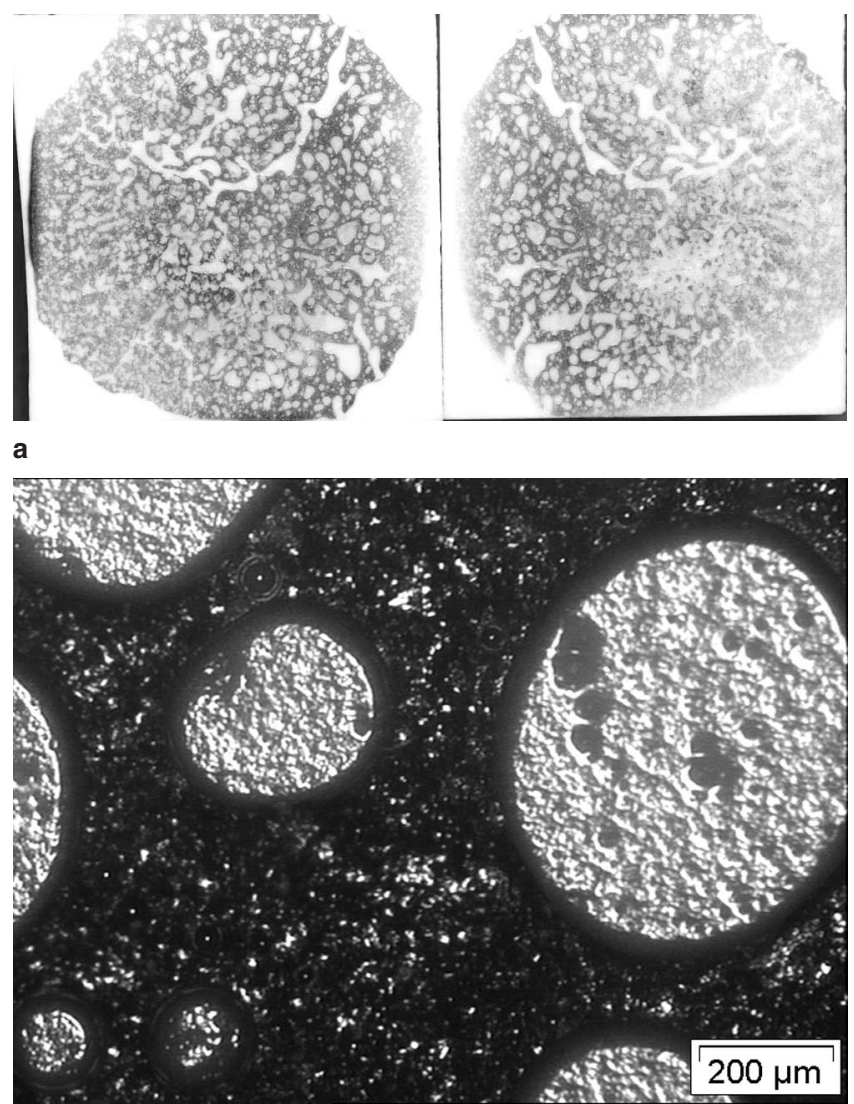

b

Fig. 9. Micrographs of ruptured surfaces of a less porous joint: (a) micrographs of mirror-ruptured surfaces and (b) high-magnification micrograph of ruptured surface.

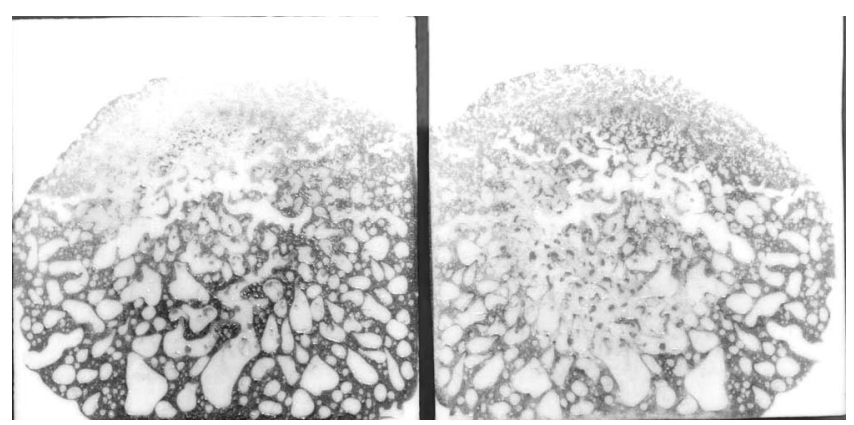

Fig. 11. Micrographs of ruptured surfaces of a very porous joint.

not always be expected to be as high as that of other joints made by welding because of the unique characteristics of their individual processes, i.e., lower melting point of the filler materials, lower bonding temperature applied, and a non-metallurgically bonded interface. Generally, the bonding strength is governed by either the filler material itself or
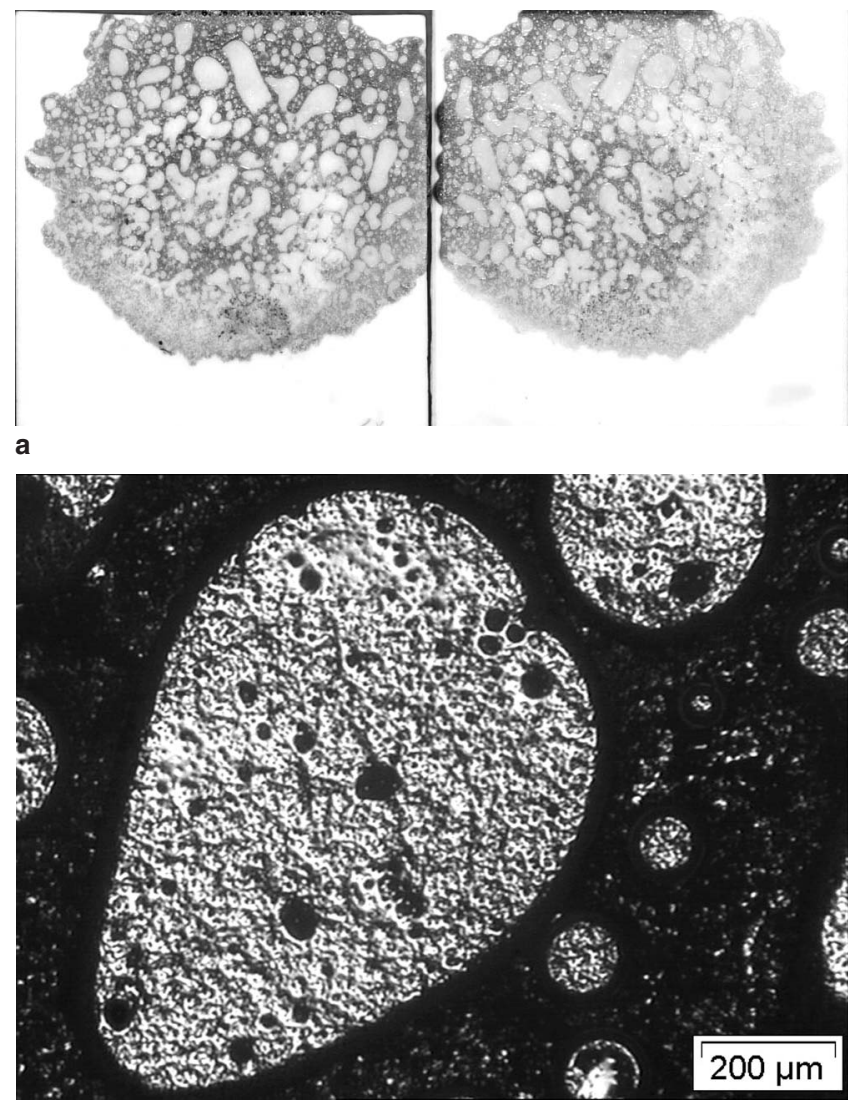

b

Fig. 10. Micrographs of ruptured surfaces of a porous joint: (a) micrographs of mirror-ruptured surfaces and (b) high-magnification micrograph of ruptured surface.

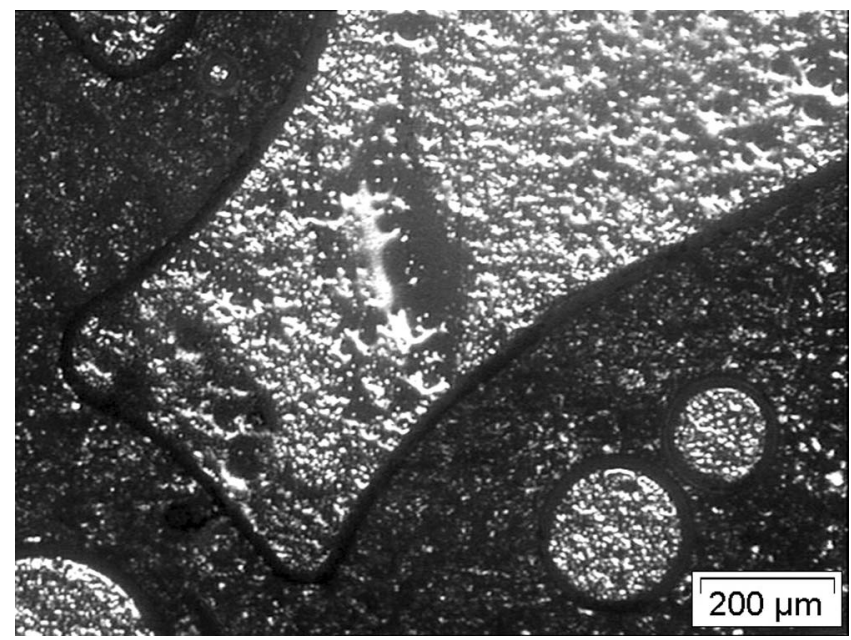

b

the interface between the filler material and the substrate.

In terms of the bonding strength of the glass-frit layer itself, it should be pointed out that both dense and porous glass-frit layers are fundamentally expected to have the identical fracture stress as long as the identical bonding parameters applied. 


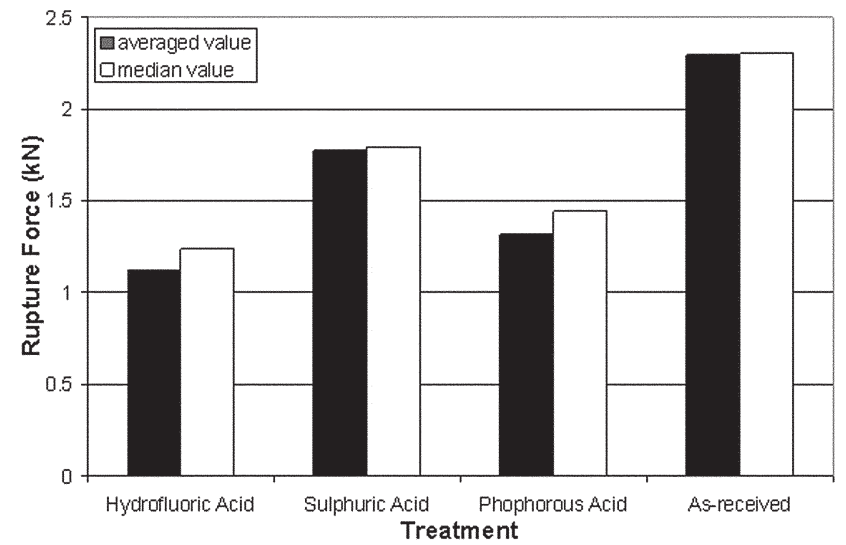

Fig. 12. Effect of surface treatment on tensile strength of SCHOTT glass-frit bonded joints.

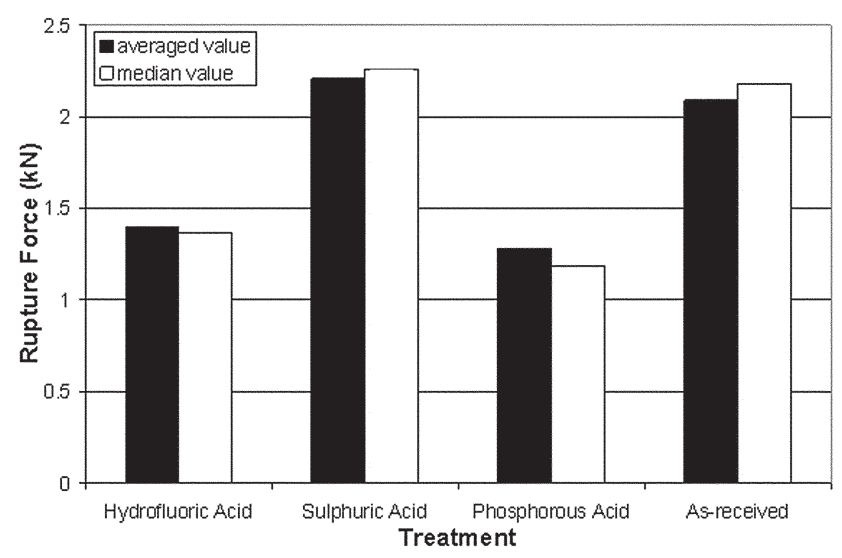

Fig. 13. Effect of surface treatment on tensile strength of SCB-15 glass-powder bonded joints.

However, this may not necessarily be true because of the ancillary effects of the voids, especially with brittle glass. Furthermore, the stress condition could be governed by the difference in morphology of the glass-frit layers, for instance, the amount and distribution of the voids.

The correlation between the treatment and the rupture force could be attributed to the difference in stress conditions the various glass-frit layers undergo during the tensile tests because of the difference in thickness of the glass-frit layer. In addition, different surface roughness could cause different contact areas, which affect bonding strength. The different etchant could also cause different surface conditions, which again influence the bonding strength.

Because the amount of each initially applied glass frit can be assumed to be identical because of the identical diameters and thicknesses, the dense ruptured joint has smaller spreading area and larger thickness, while the porous ruptured joint has larger spreading area and smaller thickness. The test results fully demonstrated this.

The absence of voids in the dense glass-frit layer may cause the glass to have an apparently higher bonding strength, which causes the failure of the bonded joint to take place in the interface between

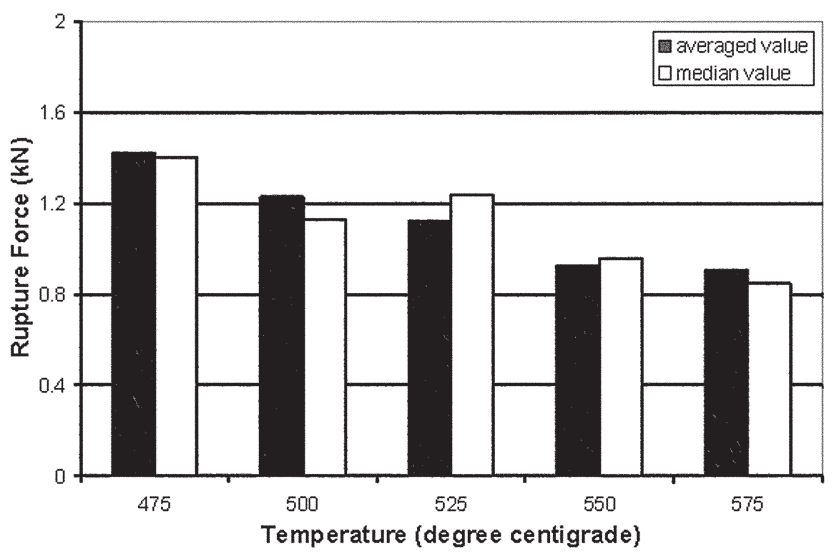

Fig. 14. Effect of bonding temperature on tensile strength of SCHOTT glass-frit bonded joints (bonding time for $15 \mathrm{~min}$ ).

the glass-frit layer and the substrate. The porous glass-frit layer might have lower bonding strength because of the presence of voids, which can cause the failure of the bonded joint taking place right in the glass-frit layer. However, the mechanism is still unclear and needs further investigation and verification.

\section{Effect of Bonding Temperatures on the Bonded Joint}

Figure 14 shows the effect of bonding temperatures on the bonded joint. All these samples were treated by $\mathrm{HF}$. The samples bonded at $475^{\circ} \mathrm{C}$ and $500^{\circ} \mathrm{C}$ exhibit the dense and less-dense ruptured joints, respectively. The samples bonded at $525^{\circ} \mathrm{C}$ show porous joints. Furthermore, samples bonded at both $550^{\circ} \mathrm{C}$ and $575^{\circ} \mathrm{C}$ display very porous joints.

It can be clearly seen that the rupture force is governed by the bonding temperature. With the increase in bonding temperature, the rupture force decreases. This could be attributed to the flowing and spreading of the melted glass frit during bonding. The higher bonding temperature causes the glass frit to more readily flow, leaving voids that reduce the bonding strength.

In terms of the bonding strength of the glass-frit layer itself, it should be pointed out that both dense and porous glass-frit layers are generally governed by bonding temperature as long as the other bonding parameters are identically applied. Therefore, the correlation between the bonding temperature and the rupture force could be readily interpreted that with the increase in bonding temperature, the rupture force (or bonding strength) decreases. Besides, correlation between rupture force (or bonding strength) and the morphology of the glass-frit layer can be observed. For example, the dense glass-frit layer might have stronger bonding strength, which causes the failure of the bonded joint taking place in the interface between the glass-frit layer and the substrate. Whereas the porous glass-frit layer might have weaker bonding strength because of the presence of voids, which causes the failure of the bonded joint taking place right in the glass-frit layer. 


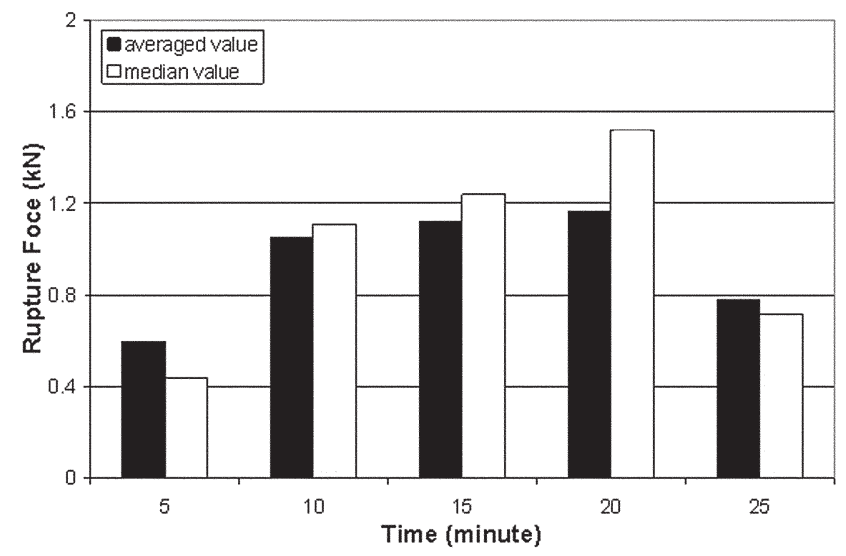

Fig. 15. Effect of bonding time on tensile strength of SCHOTT glassfrit bonded joints (bonding temperature at $525^{\circ} \mathrm{C}$ ).

\section{Effect of Bonding Time on the Bonded Joint}

Figure 15 shows the effect of bonding time on the bonded joint. All these samples were treated by HF. The samples bonded for 5 min exhibit a dense ruptured joint but with a much smaller spreading (or contact) area. The samples bonded for 10 min show less dense ruptured joints. The samples bonded for both $15 \mathrm{~min}$ and $20 \mathrm{~min}$ display porous joints, whereas samples bonded for 25 min demonstrate very porous joints. It can be seen that there is no linear correlation between the bonding time and the rupture force. With the increase in bonding time, the rupture force initially increases, then maintains at certain level, and then decreases with the further increase in bonding time. The correlation shows that the highest rupture force can be achieved if a bonding time between $10 \mathrm{~min}$ and $20 \mathrm{~min}$ is applied. This could be ascribed to the flowing and spreading of the glass frit during bonding. Shorter bonding time (for instance, $5 \mathrm{~min}$ ) could cause the glass frit to flow and spread insufficiently and leave a much smaller spreading area (or contacting area) even though the ruptured joint is dense, which failed to withstand high rupture force. In contrast, longer bonding time has the same effect as the higher bonding temperature on the bonded joint, which caused the glass frit to be overflown and overspread, and thus leave voids, because of the longer bonding time. In another word, with an increase in spreading area of the dense or less-dense ruptured joint, the bonding strength increases. However, with further increase in spreading area of the ruptured joint caused by longer bonding time, the glass-frit layer tends to form a porous or very porous joint, which will cause the bonding strength to decrease.

\section{Effect of Applied Loading on the Bonded Joint}

Figure 16 shows the effect of applied load on the bonded joint. All these samples were treated by HF. All the samples bonded at $1 \mathrm{~kg}, 5 \mathrm{~kg}$, and $9 \mathrm{~kg}$ of loading exhibit a less-porous ruptured joint. Although the samples with $9 \mathrm{~kg}$ of applied loading

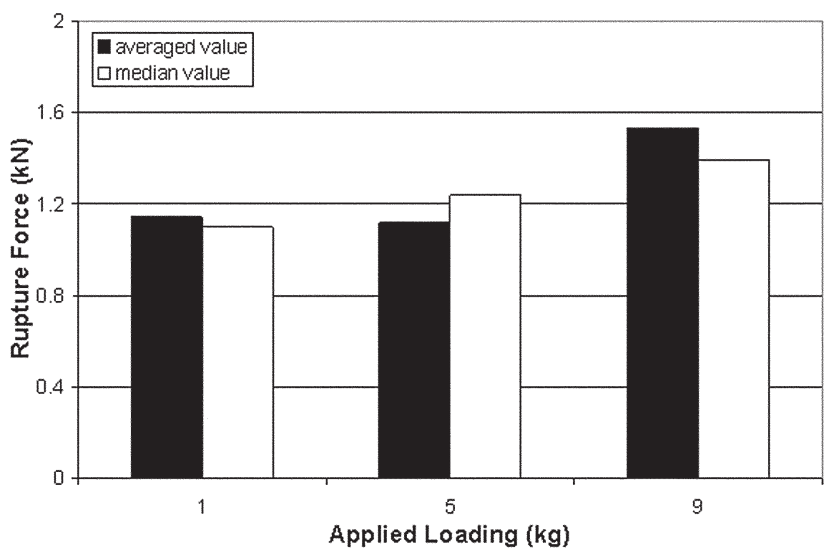

Fig. 16. Effect of loading on tensile strength of SCHOTT glass-frit bonded joints.

achieved the highest value of the rupture force, the changes were marginal. Therefore, there is no significant effect of applied loading on bonded joint in the range between $1 \mathrm{~kg}$ and $9 \mathrm{~kg}$.

\section{CONCLUSIONS}

Furnace bonding of ceramics using solder glass frit was investigated in this paper. Effects of surface treatment and bonding process parameters were evaluated. The following conclusions can be drawn from this study.

- Results show that the bonding strength of the bonded joints is mainly governed by the bonding temperature, bonding time, and surface roughness.

- It was found that surface treatment is not necessarily positive in promoting bonding strength in ceramics bonding when using solder glass frit.

- The study verified that the mechanism of ceramics bonding using solder glass frit is fundamentally different from that of conventional brazing, soldering, or adhesive bonding process. The capillary effect does not work effectively during ceramics bonding using solder glass frit because the bonding strength is not governed by surfacecontact angle.

- Density and spreading area of the glass-frit layer play important roles in bonding strength. The appropriate combination of density and spreading area can produce optimum bonding strength.

- The study demonstrates that ceramics bonding using solder glass frit is promising. Both mechanically strong and hermetically sealable joints can be produced with appropriate bonding conditions.

- Ceramic bonding using solder glass frit could be a potential process for many engineering and electronic applications.

\section{ACKNOWLEDGEMENTS}

The authors thank Mr. P.C. Lim, Ms. Y.C. Liu, Ms. H. Xie, and Mr. Y.K. Tan for their help in the experiments. 


\section{REFERENCES}

1. M.W. Barsoum, Fundamentals of Ceramics (New York: McGraw-Hill, 1997), pp. 291-330.

2. R.E. Smallman and R.J. Bishop, Modern Physical Metallurgy and Materials Engineering, Science, Process, Applications (Oxford: Butterworth-Heinemann, 1999), pp. 320-350.

3. W.F. Smith, Principles of Materials Science and Engineering (New York: McGraw-Hill, 1996), pp. 581-657.

4. M.P. Groover, Fundamentals of Modern Manufacturing Materials, Processes, and Systems (Upper Saddle River, NJ: Prentice-Hall, 1996), pp. 162-182.

5. R.W. Messler, Jr., Joining of Advanced Materials (Boston: Butterworth-Heinemann, 1993), pp. 431-456.

6. M.M. Schwartz, Ceramic Joining (Materials Park, OH: ASM International, 1990), pp. 17-40, 45-145.

7. SCHOTT AG, www.schott.com/english/index.html.

8. L.P. Connor, R.L. O'Brien, and W.R. Oates, Welding Handbook, vol. 3, Materials and Applications, 8th ed. (Miami, FL: AMS, 1998).

9. Greg Geiger, Am. Ceramic Soc. Bull. 69, 5 (1990).
10. T.H. North, Proc. International Institute of Welding Congress on Joining Research (New York: Chapman Hall, 1990).

11. G. Wallis, J. Dorsey, and D. Pomerantz, Welding J. 49, 852 (1970).

12. V. Dragoi, M. Alexe, M. Reiche, and U. Goesele, Proc. Int. Semiconductor Conf. (Piscataway, NJ: IEEE, 1999), pp. 443-446.

13. M. Esashi, A. Nakano, S. Shoji, and H. Hebiguchi, Proc. 5th Int. Conf. on Solid-State Sensors and Actuators and Eurosensors (Lausanne, Switzerland: COMST, 1989), pp. 931-934.

14. W.H. Ko, J.T. Suminto, and G.J. Yeh, Proc. Micromachining and Micropackaging of Transducers (New York: Elsevier, 1985), pp. 41-61.

15. B.C. James and D.J. Kilpatrick, TWI J. 5, 349 (1996).

16. I.A. Bucklow, TWI J. 2, 128 (1993).

17. L.A. Field and R.S. Muller, Proc. 5th Int. Conf. on SolidState Sensors and Actuators and Eurosensors (Lausanne, Switzerland: COMST, 1989), pp. 935-938.

18. Z. Sun, D. Pan, J. Wei, and C.K. Wong, "Development of Bonding Processes for Joining Glasses, Ceramics and Metals," Project Report C01-P-146AR (Singapore: Singapore Institute of Manufacturing Technology, 2003). 